\title{
Cleanliness may cultivate drug resistance
}

Cite as: CMAJ 2019 April 29;191:E482. doi: 10.1503/cmaj.109-5743

Posted on cmajnews.com on Apr. 9, 2019.

G ood hygiene is key to infection control but it may be contributing to growing drug resistance, according to a new study in Nature Communications.

Researchers at Graz University of Technology in Austria compared the microbial diversity of highly sanitized environments, including an intensive care unit, to public and private buildings with hardly any microbial controls. They found that environments with stronger hygiene measures were "microbial wastelands" where fewer microorganisms survived. The microorganisms that did survive, however, had a greater diversity of resistances. These tougher bugs show a high potential for combining with pathogens, according to study leader Dr. Alexander Mahnert.

By contrast, dirtier areas had more diverse microbial makeups that "shield against the invasion of pathogens," in the same way that diverse ecosystems are more resilient against invasive species. They also hosted more potentially beneficial bacteria. Based on these results, "it is conceivable that the restoration of biodiversity may allow a decrease of antibiotic resistance," Manhert and colleagues concluded.

The study builds on growing evidence of the collateral health damage of the modern world's obsession with cleanliness. Expo-

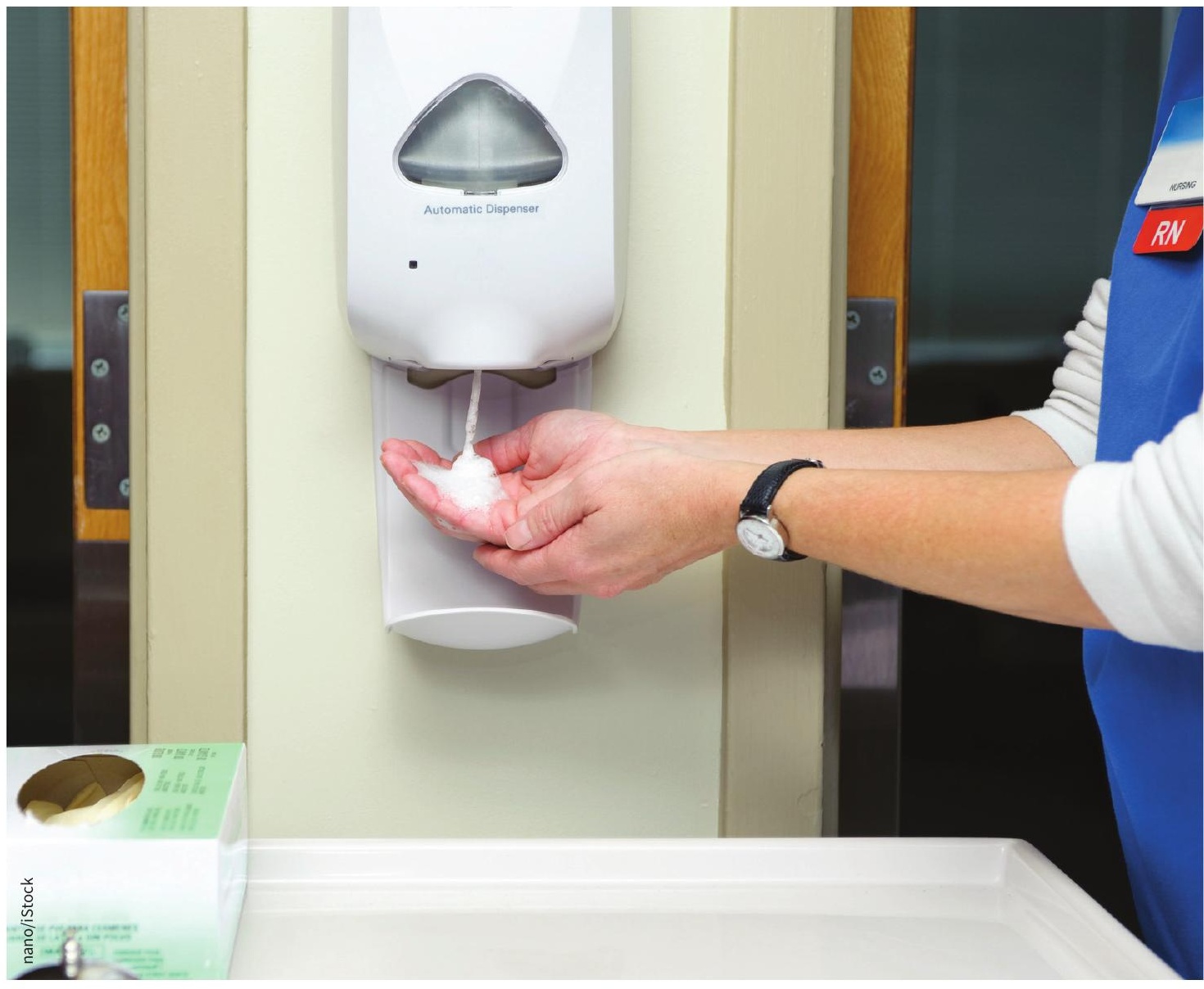

Is there such a thing as too clean? New research links excessive hygiene to drug resistance.

sure to antibiotics has been linked to increased risks for a variety of conditions, from obesity and diabetes to allergies and asthma. Meanwhile, antimicrobial resistance is predicted to cause 10 million deaths a year worldwide by 2050 .

According to Mahnert and colleagues, "human exposure to almost sterile environments should be limited to operating rooms or particular industrial processes." In all other areas of health care and life, regular airing, houseplants, the deliberate use of useful microorganisms and the reduction of disinfectants and antibiotics could improve microbial diversity and health. In the future, they argue, "the presence of highly diverse, stable, and beneficially designed microbiomes inside healthy buildings could result in lower exposures to resistances."

Lauren Vogel, CMAJ 